\title{
Crisis Pregnancy Centers in Canada and Reproductive Justice Organizations' Responses
}

\author{
Haiqi $\mathrm{Li}^{1}$ \\ ${ }^{1}$ The Cambridge School of Weston, Weston, Massachusetts, USA \\ Correspondence: Haiqi Li, The Cambridge School of Weston, Weston, Massachusetts 02493, USA. E-mail: \\ lihaiqi.good@hotmail.com
}

Received: November 27, 2018 Accepted: December 23, 2018 Online Published: January 8, 2019

doi:10.5539/gjhs.v11n2p28

URL: https://doi.org/10.5539/gjhs.v11n2p28

\begin{abstract}
The spread of crisis pregnancy centers (CPCs) has become an alarming issue in the fields of public health and reproductive justice (RJ) as they impede women's fully-informed decisions and threaten women's reproductive autonomy. However, most existing scholarship has only focused on CPCs within the United States; hardly any literature has been devoted to anti-CPC activism. This study contributes to addressing these gaps by adopting a mixed method. The paper first reviews the status quo of U.S. and Canadian CPCs through the existing literature to contextualize my investigation. Then it explores the establishment of individual Canadian CPCs to evaluate whether they are gaining more influence. It also analyzes the presence and absence of information on Canadian anti-CPC activism in the social media of RJ organizations. Finally, it examines the interviews I conducted with Canadian RJ activists to identify the ongoing anti-CPC activism and why some groups do not regard it central to their agenda. Results of this research reveal that CPCs have been continuously expanding in Canada during the past 35 years. Despite realizing their threat, most Canadian RJ groups do not focus their activism on CPCs and instead, concern themselves more with such issues as abortion access owing to their political engagement restriction, as well as their viewpoint that variation among Canadian CPCs and the Canadian liberal political context lessen CPCs' overall threat. The limited ongoing activism includes lobbying for halting funding for CPCs, revoking their charitable statuses, banning their advertisements, and removing their biased sex education from public schools.
\end{abstract}

Keywords: anti-abortion activism, Canada, Crisis Pregnancy Center, equity in health, pro-choice activism, reproductive justice, reproductive right

\section{Introduction}

A 2016 study by the Abortion Rights Coalition of Canada (ARCC), Review of "Crisis Pregnancy Centre" Websites in Canada (Arthur et al., 2016), drew significant attention from both sides of the Canadian "abortion war." An anti-abortion activist described the study as "witch hunts" (Maloney, 2017). A humanist association referred to it as "a hugely important study" (BC Humanist Association, 2016); similarly, a feminist organization considered it "important to keep in mind" (Laurier Brantford Women's Centre, 2016). One of the very few reports that investigate Crisis pregnancy centers (CPCs) in Canada, this report specifically focuses on how these centers' websites distribute misinformation and withhold facts. Reproductive justice (RJ) activists found this report significantly constructive because CPCs now outnumber abortion providers in Canada, thus posing a threat to women's reproductive freedom.

Crisis pregnancy centers, sometimes referred to as pregnancy resource centers (Bryant, Narasimhan, Bryant-Comstock, \& Levi, 2014), are religiously-informed non-profit organizations operating all over the world, most of which are connected with one or more umbrella organizations. These centers claim to provide a range of free services, including pregnancy counseling, ultrasound technology, pregnancy and STI tests, prenatal care, maternity resources, and baby items, in order for pregnant women to better understand their options. In practice, however, they often utilize medically-inaccurate information to discourage women from having abortions. Moreover, oftentimes CPCs pathologize and stigmatize abortion by using the term "post-abortion trauma" that is unrecognized in the medical field (Bryant \& Levi, 2012). The vast number of CPCs further increases the danger of them - more than four thousand CPCs are currently operating in the U.S (4189; Heartbeat International, n.d. b) and more than two hundred are currently operating in Canada (231; Heartbeat International, n.d. a), threatening the 
reproductive agency and autonomy of all women with unintended pregnancies who enter these centers by impeding their fully-informed decisions. What is even more concerning is that CPCs outnumber abortion providers in the United States (U.S.) by a ratio of at least two to one (Holtzman, 2017) and in Canada by about 1.7 to 1 (231 CPCs to 124 abortion providers; Paperny, 2015).

It seems astonishing, however, that academic discussion about CPCs has so far been centered only in the United States; only one scholarly article has addressed CPCs in Canada. This huge gap in scholarship has left a range of questions unanswered about Canadian CPCs. This paper aims to contribute to filling some of this blank space by specifically answering the following questions: What is the status quo of Canadian CPCs? If they are decreasing in number, what has led to their loss of influence? If their number is growing, what are Canadian reproductive justice groups doing to counter their increasing impact? What, if any, does such anti-CPC activism encompass? Conversely, what factors have prevented reproductive justice groups from focusing on this issue? This paper adopts multiple methods to answer these questions. It expands upon the existing scholarship, investigates the information provided on the media of both CPCs and reproductive justice groups, and analyzes interviews I conducted with RJ groups to show the status quo of CPCs in Canada as well as pro-choice activists' reactions to these centers' influence.

In what follows, I first review the scholarship on CPCs currently available in the United States and Canada in order to describe the overall status quo of CPCs in Canada and offer a greater context for my analysis of Canadian anti-CPC activism. In Section 3, I study the establishment and growth of CPCs in Canada to evaluate whether they are gaining more influence in this country. Then, in Section 4, I analyze the information present on the websites and social media of Canadian reproductive justice organizations and what it implies about Canadian anti-CPC activism. Finally, I examine the interviews I conducted with reproductive justice activists from Canada to find out what forms of anti-CPC activism are existent in Canada and why some activist groups do not regard anti-CPC action as a central part of their agenda.

\section{Literature Review: Contextualizing CPCs and Anti-CPC Activism in Canada}

Before reviewing published articles about CPCs in Canada, I will first examine scholarly articles about CPCs in the United States, because current scholarship has mostly discussed these centers within the U.S. context. The ways CPCs run in the United States have been well-documented in regard to their deceptive practices (Bryant et al., 2014; Bryant \& Levi, 2012; Chen, 2013), the sources of their funding (Chen, 2013; United States House of Representatives Committee on Government Reform Minority Staff Special Investigations Division, 2006) and why attempts to regulate them have failed during the past few years (Bryant \& Swartz, 2018; Chen, 2013; Hill, 2015).

For instance, public health scholars Bryant, Narasimhan, Bryant-Comstock, and Levi (2014), in their article "Crisis Pregnancy Center Websites: Information, Misinformation and Disinformation," systematically review the medically inaccurate information provided by U.S. CPCs on their websites. This research concentrates on the websites of those CPCs listed in the resource directories from the states that require a waiting period for pregnant women to obtain an abortion. The researchers conclude that $80 \%$ of crisis pregnancy centers, on their websites, offer misstatement concerning the risks of abortions (Bryant et al., 2014); the researchers also demand that the aforementioned states exclude these websites from their resource directories (Bryant et al., 2014).

Another example of this type of scholarship is "Crisis Pregnancy Centers: Impeding the Right to Informed Decision Making" by Amy Chen (2013), a legal scholar. In this article, Chen highlights how, over the course of 2003-2013, CPCs have been given "millions of dollars in funds and grants from federal and state governments" (Chen, 2013), specifically through "the Community-Based Abstinence Education Program" (Chen, 2013), "the Title V Abstinence-Only Program" (Chen, 2013), and "“Choose Life' license plates” (Chen, 2013) - a program that subsidizes pro-life organizations with profits from selling license plates. Chen also contends the reason why federal courts have rejected local governmental ordinances demanding CPCs to clarify their anti-abortion stance is that the courts have considered CPCs' speech as individual speeches. In other words, the federal courts have not evaluated CPCs' speech as professional or commercial, and thus have applied strict scrutiny to legislation that constrains CPCs' freedom of expression. One may ask, then, whether similar statutes to regulate CPCs would be more readily passed if proposed in Canada, since a previous court case has shown that The Canadian Charter of Rights and Freedoms would likely justify limiting CPCs' freedom of speech in order to "[protect] the health and safety of citizens" (West Coast Legal Education and Action Fund, 2008). This question is difficult to answer by drawing from the current scholarship on CPCs because this body of work has largely ignored CPCs outside of the U.S. context, as mentioned above.

In fact, just one scholarly article addresses Canadian CPCs directly. In this article, entitled "Toll Free but Not 
Judgment Free: Evaluating Postabortion Support Services in Ontario" (LaRoche \& Foster, 2015) and published in the reproductive health journal Contraception, public health researchers LaRoche and Foster conduct a telephone-based mystery client survey on post-abortion advising in Ontario, Canada. The authors, drawing from the responses they collect, argue that the unprofessional counselors from CPCs tend to use humiliating and "stigmatizing language" (LaRoche \& Foster, 2015) in their post-abortion counseling services.

Aside from this scholarly investigation, only four other research reports published by Canadian reproductive justice activist organizations focus on CPCs. Three of these works, respectively, show that women's centers and service agencies in British Columbia are often unaware of CPCs' agendas (Arthur, 2009), advise the Canadian government to create a website that provides comprehensive, unbiased guidance on abortions (Gonin, Pronovost, \& Blais, 2014), and expose that 58 CPCs, being charities, obtained "around $\$ 3.5$ million" from Canadian governmental sponsorship during "2011 to 2015" (Abortion Rights Coalition of Canada [ARCC], 2017). CPCs' major governmental grants, according to the third report, come from federal programs including Canada Summer Jobs (CSJ) and Employment and Social Development Canada (ESDC), as well as provincial programs like Family and Community Support Services (FCSS) in Alberta (ARCC, 2017). The government granted the above funding mainly based on CPCs' charitable statuses and eligible services, such as offering summer job positions for young people (ARCC, 2017). However, since these centers effectively work to discourage women from making well-informed choices on their reproductive affairs, the legitimacy of such funding should be questioned (ARCC, 2017).

The fourth and the latest report by the Abortion Rights Coalition of Canada (ARCC), entitled Review of "Crisis Pregnancy Centre" Websites in Canada (Arthur et al., 2016), seems to play an influential role in advancing Canadians' understanding of CPCs, since it has been frequently referred to by different activist organizations when asked about CPCs (Note 1). This report analyzes the websites of 166 Canadian CPCs by examining whether they provide specific misinformation. It discovers that $48 \%$ of the websites include assertions of abortions' damaging psychological effects that are medically unrecognized, and $5 \%$ offer misstatements "about contraception or sexually-transmitted infections" (Arthur et al., 2016). What's more, the researchers argue that many CPCs have already entered Canadian public schools to teach their biased sex-education programs (Arthur et al., 2016).

By paralleling this ARCC report with the aforementioned journal article "Crisis Pregnancy Center Websites: Information, Misinformation and Disinformation" (Bryant et al., 2014), one can draw the conclusion that many CPCs in Canada and in the United States deploy similar deceptive tactics on their websites, including asserting an association between abortions and breast cancer (5\% for CPCs in Canada (Arthur et al., 2016) and 20\% for CPCs in the United States (Bryant et al., 2014)) as well as linking abortions to the so-called post-abortion stress (48\% for CPCs in Canada (Arthur et al., 2016) and 73\% for CPCs in the United States (Bryant et al., 2014)). However, it is worth noting from the above statistics that such misinformation is utilized less frequently on websites of Canadian CPCs than on the websites of their U.S. counterparts. One may question whether such a difference is a factor that may lead Canadian pro-choice groups to place less focus on CPCs. Again, this inquiry is hard to answer by merely reviewing the existent scholarship.

While studies on CPCs have been predominantly centered within the U.S. context, scholars have largely neglected anti-CPC feminist activism in both the United States and Canada. The only notable exception to this statement is the article "Abortion as Gender Transgression: Reproductive Justice, Queer Theory, and Anti-crisis Pregnancy Center Activism" (Thomsen \& Morrison, in press) that is not yet published. In this paper, Thomsen and Morrison examine the campus-based anti-CPC activism by End Fake Clinics (EFC), a student group at the University of California, Santa Barbara (Thomsen \& Morrison, in press). According to Thomsen and Morrison, their forthcoming article is the only scholarship that concentrates on anti-CPC activism (Thomsen \& Morrison, in press). Furthermore, the authors argue that CPCs are "much more central to the anti-abortion movement" than anti-CPC work is to the pro-choice movement (Thomsen \& Morrison, in press).

Although their article solely focuses on anti-CPC activism in the United States, it is useful for thinking about such activism beyond the U.S - particularly because there is no scholarship on this topic in Canada. Specifically, the strategies adopted by EFC and mentioned in this article helped me devise interview questions to investigate whether Canadian reproductive justice groups use similar approaches to counter the influence of CPCs. Such strategies include photography campaigns to strengthen the awareness about CPCs, working with a school legislative body to prohibit CPCs from advertising on campus, running workshops and academics seminars (Thomsen \& Morrison, in press), and screening a documentary on CPCs (Thomsen \& Morrison, in press).

By reviewing the above scholarship and activists' reports, I aim to construct a clearer picture of the overall landscape of CPCs and anti-CPC activism in Canada. Yet, due to the lack of academic focus on these topics to date, 
limited conclusions can be drawn. It can be inferred from the article by LaRoche and Foster, the report by ARCC, and the broader discussion about CPCs in general, that CPCs in Canada and the services and information they offer indeed infringe on the fully-informed decisions entitled to Canadian pregnant women. What cannot be proven by the work above, however, is the current dynamics of CPCs in Canada - that is, whether their number is steadily growing, remaining stagnant, or gradually shrinking. If they are expanding, are Canadian reproductive justice organizations acting to counter their influence? If so, what does such activism involve? Are these groups engaging in anti-CPC activism that is not evident online? If the groups are not taking action, what factors have contributed to their lack of focus on CPCs? These questions are the main focuses of the following sections. The next section specifically documents the overall growth and decline of Canadian CPCs by studying the dates of their establishment and closure.

\section{Establishment and Growth of Canadian CPCs (Note 2)}

\subsection{Methods of Accessing Individual CPCs' Years of Establishment}

In this study, I only selected CPCs affiliated with one major umbrella organization, the Canadian Association of Pregnancy Support Services (CAPSS). When I conducted this investigation in August 2018, this organization's website listed 70 CPCs with links to their official web presences (Canadian Association of Pregnancy Support Services [CAPSS], n.d. b), including official websites, Facebook and Twitter pages. The CPCs listed on the CAPSS website accounted for about $30.3 \%$ of all CPCs in Canada (70 out of all 231 CPCs in Canada, Heartbeat International, n.d. a). I developed a protocol in order to find the years when each of these Canadian CPCs was established.

First, I performed a search within CAPSS's official Facebook "Posts" section using the keyword "introduce" along with each center's name. I based this method upon CAPSS's weekly practice of introducing its affiliated CPCs.

Second, I retrieved the official websites of individual CPCs. I ran browser searches with the keywords "found," "establish," "start," and "open" within their Main page, About page, and News \& Events section (if applicable). I also used the internal search functions of each website when it was available to search for the same set of keywords and access more information about these CPCs' foundation.

Third, I accessed the official Facebook pages linked to on individual CPCs' official websites (if available). I looked at the "About" and "Posts" sections of these Facebook pages and reran browser text searches with the keywords "found," "establish," "start," and "open."

In the cases when none of the methods above yielded an individual CPC's year of establishment, I performed a Google search using the name of this center with the aforementioned keywords. If a Google search still did not provide the data needed, I would perform a search within the Canadian Government's Registered Charity Listing (Government of Canada, n.d.) with this center's name, and then access the charity's (CPC) detail page. This method was informed by the finding from Review of "Crisis Pregnancy Centre" Websites in Canada (Review of Websites) that $68 \%$ of the Canadian CPCs identified by ARCC researchers were charities (Arthur et al., 2016). However, I did not prioritize this method, taking into consideration that the "[e]ffective date of [charity] status" of a CPC provided in the charity database might be later than the exact year when it was founded.

\subsection{Results of CPC's Years of Establishment in Canada, Compared with Other Available Data}

Out of the 70 listed CPCs from CAPSS directory, I managed to access 57 CPCs' years of foundation using the first three methods listed above; seven CPCs had the data accessible through the Google Search procedure (specifically on LinkedIn, in a town governmental letter, in a local community service database, and in a news report); I discovered 4 CPCs' charity registration dates using the Charity Listing Search. However, I was not able to access two centers' years of foundation applying any of the approaches above. It is worth noting only one out of the 70 CPCs claimed permanent closure on its website, whereas the other 69 centers all seemed to be currently functional based on the information presented on their websites or social media accounts as of August 2018. I compiled Figure 1 based on the dates of CAPSS-affiliated CPCs' foundation and closure. 


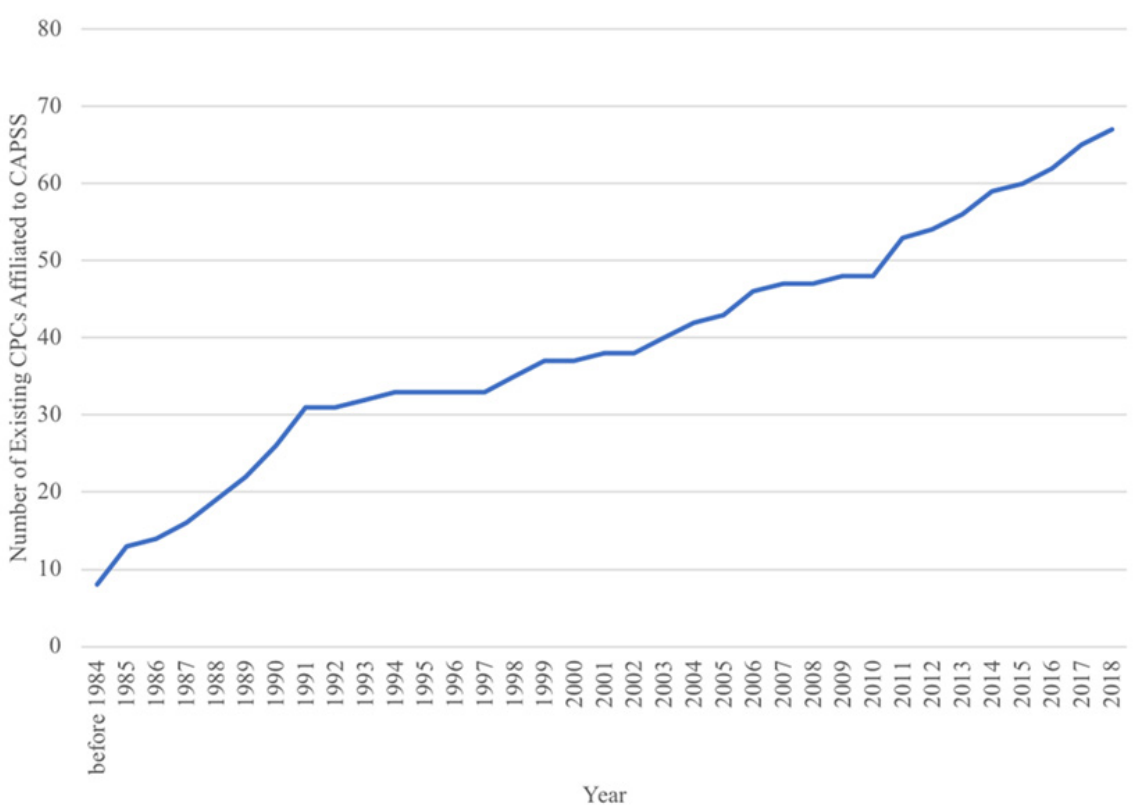

Figure 1. Number of Existing CPCs Affiliated to CAPSS

Note. I created Figure 1 based on Individual CAPSS-affiliated CPCs' years of establishment. Only sixty-seven centers were plotted in this graph for 2018 because two centers' years of foundation were not accessible online and one reported itself to be closed.

From the information I collected above, I inferred that CPCs have generally been growing in Canada over the past 35 years. Therefore, I plotted Figure 2 as an extrapolation of Figure 1, estimating how CPCs throughout Canada increased in number. Figure 2 assumes that CAPSS-affiliated CPCs have always taken up a mostly constant proportion of all CPCs throughout Canada (30.3\%) and, therefore, the growth of CAPSS-affiliated CPCs can also reflect the growth of all CPCs in Canada.

$$
250
$$
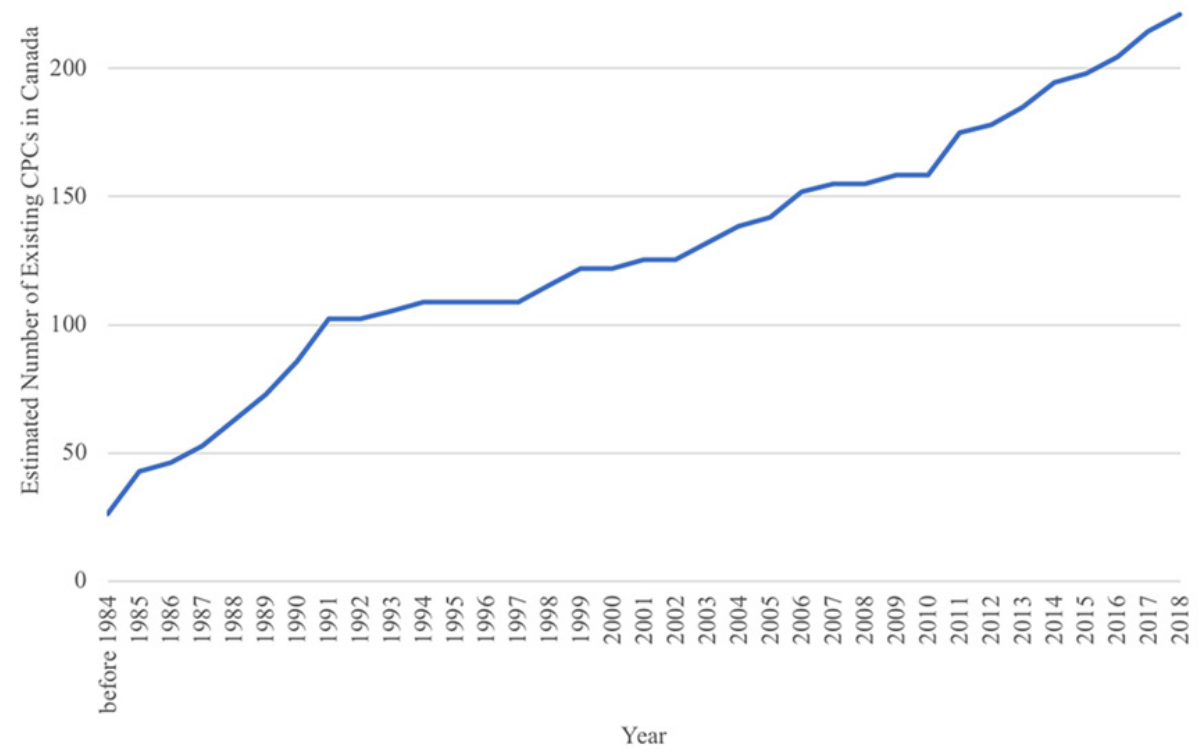

Figure 2. Estimated Number of Existing CPCs in Canada (Extrapolated from Existing CPCs Affiliated to CAPSS) Note. I created Figure 2 from extrapolating the trend of growth for CAPSS-affiliated CPCs. 
Realizing that limited statistical inference can be made from this extrapolation, I also considered another source of data for comparison. In the aforementioned report Review of Websites by ARCC, the researchers state that they compile a list of "all current CPCs in Canada: 180" (Arthur et al., 2016); the time when the researchers first collected the data on all CPCs was August 2014 and they verified these 180 CPCs "as operational as of mid 2015" (Arthur et al., 2016). However, as of August 2018, 231 CPCs were functioning in Canada according to the Worldwide Directory of Heartbeat International (Heartbeat International, n.d. a). This numerical difference suggests a growth of about 51 CPCs between 2014 and 2018. Admittedly, ARCC researchers might omit to include all Canadian CPCs during their investigation, but merely the error or omission in their researching process was not likely to account for such a huge difference. Thus, this data provided some support for the claim that CPCs have been continuously growing in Canada during the past five years.

In summary, the results of my investigation suggest that there has been a constant increase in the number of Canadian CPCs over the last 35 years. The next two parts of this paper explore what reproductive justice activists have done in response to CPCs' expanding influence.

\section{Information about CPCs and Anti-CPC Activism on the Social Media of Canadian RJ Organizations (Note 4)}

\subsection{Methods of Accessing the Social Media of Anti-CPC Canadian Activists}

To understand whether and how reproductive justice activist groups in Canada address the steadily increasing CPCs, I chose to first examine the websites and social media of a Canadian nation-wide pro-choice organization, ARCC, as well as twenty-one other functioning pro-choice groups listed by ARCC (ARCC, n.d.). This study defines a reproductive justice group as "addressing CPCs" if it takes concrete measures to counter the influence of local or nationwide CPCs beyond simply mentioning these centers on its social media or referring to other groups' studies. Attempts to "address CPCs" include but are not limited to: doing educational outreach to citizens in nearby communities, conducting investigations on CPCs, launching campaigns or petitions to pass municipal, provincial or national statutes to regulate CPCs, and working to remove CPCs' misleading sex education programs from schools. In what follows, I describe my method of accessing these $22 \mathrm{RJ}$ groups' social media coverage on anti-CPC activism.

First, I accessed the About pages on these pro-choice organizations' various forms of web presence (official websites, Facebook or Twitter pages) to determine whether they fulfilled the requirements of this study. In this step, I identified two groups as respectively a sexual health activist group and an abortion providers' coalition, rather than activist groups. (Note 5) I also excluded one organization that operated only in a region under little or no influence of CPCs, that is, in a province with only one CPC. (Note 6)

Next, I accessed the web presences for the remaining 19 groups. For groups that had official websites, I performed browser text searches with the keywords "crisis pregnancy centre" and "pregnancy resource centre" (Note 7) within the About Us, Goals, Action/Campaigns and News \& Events sections on their websites. In cases when search buttons were available on their websites, I also applied the same set of keywords to searches in their internal search system. For each organization that used Facebook or Twitter or both to publicize its agenda and movement, I ran the search function in the Facebook Posts section and the Twitter Advanced Search with the same set of keywords and its account ID. 


\title{
4.2 Results
}

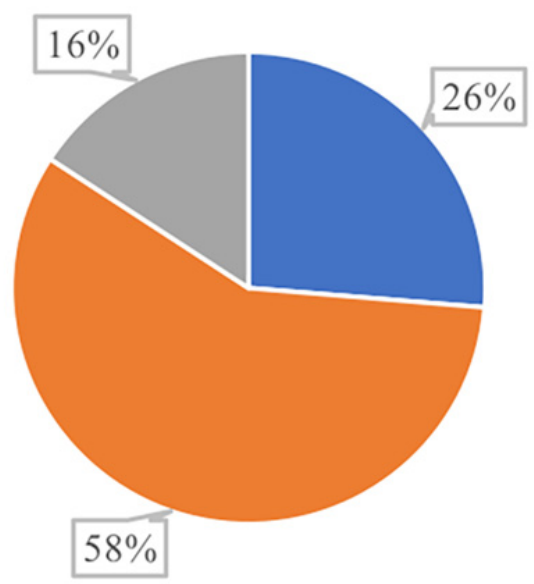

\author{
- No information on CPCs \\ - Only included information on CPCs but no information on the group's \\ efforts/campaigns against $\mathrm{CPCs}$ \\ " Included studies about CPCs or campaigns against CPCs for supporters of the \\ group to participate in
}

Figure 3. Information about CPCs on the Social Media of Canadian Anti-Abortion Activists

Note. Figure 3 offers a visual representation of the information I collected. Five (26\%) out of the 19 reproductive justice groups did not mention CPCs in any way on their websites and social media; 11 groups (58\%) only mentioned materials pertaining to CPCs in general-including previous news articles and ARCC's Review of Websites - but did not reveal any of their own efforts or campaigns against CPCs'; only three groups (16\%) mentioned investigations they had conducted on CPCs or campaigns for their supporters to join in.

This result revealed a scarcity of serious activism against CPCs within Canadian pro-choice societies' social media as of August 2018. For instance, on the official website of Action Canada for Sexual Health and Rights - a sexual and reproductive rights association that grew out of three former national organizations (Action Canada for Sexual Health and Rights, n.d.) - no information pertaining to CPCs appeared in the subsection "Our Campaigns" under "Our Work" section. Within the "Campaigns" subsection under "Resource," the only information relevant to CPCs listed was Review of Websites by ARCC. Meanwhile, its internal search engine only displayed six results when I entered the keywords "crisis pregnancy centre"; only four of these results effectively contained these three keywords as a whole phrase. Yet in fact, these pages, simply referred to the report by ARCC, a game made by another organization that included instruction on how to identify CPCs (Note 8), the aforementioned academic journal article "Toll Free," (LaRoche \& Foster, 2015), and a news article, instead of any description of this society's work against CPCs. Searching for "pregnancy resource centre" also did not yield any further information related to CPCs.

One may reasonably assume that some kinds of anti-CPC activism still take place outside of these groups' social media. Therefore, the next section is devoted to discussing the process and results of reaching out to these pro-choice groups and conducting interviews.

\section{Responses from Reproductive Justice Organizations}

\subsection{Reaching out to Reproductive Justice Groups in Canada and Developing Interview Protocols}

Assuming that there may be some forms of anti-CPC activism not present or evident online in RJ groups' social media, I reached out to the aforementioned nineteen groups through their email addresses and Facebook pages during August 2018. Specifically, I asked whether they took measures to counter CPCs' influence, as well as whether any of their members would be willing to participate in an interview. I framed the request for an interview in a way that invited both groups that did or did not address CPCs, in an attempt to explore more comprehensive reasons why certain RJ organizations did not engage in anti-CPC activism while also situating the anti-CPC activism in the overall Canadian RJ work. 
For each group that answered my question, I documented their responses and any relevant materials that they referred to. I also compared their responses with my previous findings from their social media to examine if any ongoing anti-CPC activism was left out of these groups' media coverage.

I conducted IRB-approved Skype interviews that lasted approximately one hour with each activist from the RJ groups that accepted my request. I voice-recorded each of these calls and transcribed them. One aim of my interview questions was to investigate forms and motivations of existent anti-CPC activism. For instance, to groups that claimed to tackle CPCs, two questions I asked were "What strategies does your organization take to address CPCs?" and "What factors have informed this strategic decision?". On the other hand, the questions also attempted to study reasons why some organizations do not deal with CPCs. The questions I used to investigate this issue include:

"I have documented an increase in CPCs in Canada in the last 35 years, but it does not seem that there has been a simultaneous increase in the focus on CPCs among RJ organizations from information shared on their media. Do you agree with this statement? If so, why do you think this is? If not, why not?"

"What are other issues, if any, that your organization (or the groups you collaborate with) considers as more urgent than CPCs?"

I also devised interview questions that inquired into the Canadian RJ groups' basic structures and forms of coalition with other organizations, so as to understand if their operating mechanism also influenced whether or not they focused on CPCs.

\subsection{Results}

Seven out of the 19 groups replied through Facebook or email. Two groups that discussed their anti-CPC work in their media (Alberta Pro-Choice Coalition and ARCC) confirmed that they are still engaging in such activism. The other five organizations, on the other hand, stated that they have not directly addressed CPCs despite acknowledging the presence of CPCs in Canada. These responses suggest that the online media of Canadian RJ groups truthfully mirrors the presence or absence of their anti-CPC advocacy; therefore, the 11 groups that did not mention their anti-CPC activism on their web presences likely did not have any ongoing activism in reality.

Additionally, six (71\%) of the seven groups referred to ARCC's "Review of Websites" as a related material in their answers. This commonality indicates that this report has significantly influenced and advanced the understanding of Canadian CPCs among most reproductive justice activists. On the other hand, this finding also suggests that the information about CPCs circulated amongst activists has not extended far beyond this report and further, confirms the paucity of such investigation into Canadian CPCs.

In the meantime, I successfully connected to representatives of three different reproductive rights groups-Ruth from Alberta Pro-choice Coalition (AB Pro-choice), Sandra from ARCC, and Ralph from Planned Parenthood Ottawa (PPO). (Interviewees are all referred to by pseudonyms in this paper and their positions are not mentioned to protect their privacy.) Among these three organizations, AB Pro-choice and ARCC engaged in ongoing anti-CPC activism at the time when I conducted the interviews. Responses collected from these interviews show that, although the ongoing activism that directly counters CPCs comprises only a small proportion of the reproductive justice work in Canada, such anti-CPC activism exists in a wide range of forms. In addition, their responses about the motivations for such activism further reveal some problematic aspects of Canadian CPCs that were not evident in the works I reviewed in Section 2. Moreover, the interviewees contended that the reasons why most groups do not address or focus on CPCs involve external limitations as well as their own evaluation of the scale of the threat that CPCs pose. The following subsections elaborate on these findings.

\subsubsection{Motivations of Existent Anti-CPC Activism, and an Expanded Understanding of Threats Posed by CPCs}

The representatives of both groups that directly address CPCs regarded the same two issues with these organizations as their major motivations for activism: the misleading information CPCs provide and the practice among CPCs of masking their real agenda. These concerns are in line with what one might expect from existent academic discussions of CPCs' threat. It is noteworthy, however, that Ruth, the representative of AB Pro-Choice, mentioned two points during our interview that had not come up in my previous research work. First, aside from CPCs' common medical misinformation, Ruth also cited these centers' biased overemphasis of open adoption as dangerous. She contended that this emphasis compels some CPC clients to choose adoption over abortion and "think that they can see the children often" after the adoption procedures, while in reality, "the adopting family can ... cut off access ... after the paper is signed." Second, Ruth pointed out that Canadian CPCs' practice of misrepresenting and beautifying their agenda - for example, by offering items that support women who choose to continue their pregnancy and thus subtly incentivizing patients to forego abortions - has enabled them to receive a 
considerable amount of governmental funding. Ruth concluded, "governments fund what appear to be benign programs - like giving out diapers, clothing and maternity homes - and provide the stable funding for CPCs to continue with their anti-choice agenda." (Rep. of AB Pro-choice, personal communication, August 14, 2018; Rep. of ARCC, personal communication, August 11, 2018)

Additionally, the sex education program some CPCs have introduced into certain Alberta public schools also has motivated AB Pro-Choice's activism against these organizations. Ruth explained that AB Pro-Choice regards the CPCs' sex education programs alarming first because these CPCs oppose contraception use and have "claimed in school that contraceptives were abortifacients." Furthermore, these CPCs' sex education programs exclude information related to LGBTQ2S sexuality, because CAPSS - one of their umbrella organizations - states in its Core Documents that it views sexuality as only "between one man and one woman" (CAPSS, n.d. a), and CPCs have to sign this document in order to become affiliated with CAPSS (CAPSS, n.d. a). One comment made by a CPC employee in response to a student's questions about LGBTQ2S sexuality, as cited by Ruth, was "we are not here to talk about that." Therefore, AB Pro-Choice views addressing CPCs' sex education, and even countering CPCs' influence in general, as having significance in relation to gender and sexual equity beyond just the pro-choice movement. (Rep. of AB Pro-choice, personal communication, August 14, 2018; Rep. of ARCC, personal communication, August 11, 2018)

\subsubsection{Forms of Ongoing Anti-CPC Activism}

Ruth from AB Pro-Choice and Sandra from ARCC both described the different forms of activism in which their organizations engage during our interviews. One major form of action taken by both groups is conducting researches and publishing reports on CPCs, for which I concluded three main objectives from their descriptions. Their first goal is to uncover CPCs' sources of funding and then to advocate to cut off such money. Second, they aim to demonstrate to different municipal governments the dangers of CPCs - specifically those within the region of each city's jurisdiction. Third, such studies can offer a rebuttal to individual CPCs that claim their exceptionalism and deny having worked to undermine pregnant women's reproductive autonomy. Regarding the third objective, Ruth mentioned that AB Pro-Choice made a report on a specific CPC in Calgary, Alberta and posted it on their social media to show that although this center claimed to be "different from other CPCs," it was in fact just as dangerous as any other CPC. (Rep. of AB Pro-choice, personal communication, August 14, 2018; Rep. of ARCC, personal communication, August 11, 2018)

Both Ruth and Sandra also talked about how their organizations work to make it more difficult for CPCs to obtain funding, maintain their charitable status, and advertise on buses or billboards. One measure taken by ARCC and $\mathrm{AB}$ Pro-Choice has been appealing to pro-choice advocates to join in their letter-writing campaigns to governmental agencies - specifically to MPs (Members of the Parliament) and provincial government ministers - calling a halt to funding for CPCs and asking for revocation of their charity statuses. For instance, one letter AB Pro-Choice has written to the Alberta government has addressed the governmental funding for parenting courses ran by a local CPC. This letter, according to Ruth, has questioned "how valuable their service [the CPC parenting course] was, especially when they ... opposed contraception use." The two organizations have also directly contacted CPCs' funders once they have discovered that these funders were possibly unaware of CPCs' anti-abortion stance. These reproductive rights activists also strive to realize their goals through some third parties. ARCC has endeavored to increase exposure of its discovery that "major CPC funding of federal level [was] from Canada Summer Jobs program" in the national news media and has contributed to successfully lobbying the federal government to prohibit anti-abortion organizations from receiving CSJ grants. On the other hand, ARCC has managed to pull CPCs advertisements off buses by submitting complaints to Advertising Standards Canada (a self-regulating body of the Canada advertising industry) and claiming that these propaganda images have contravened the Canadian Code of Advertising Standards. (Rep. of AB Pro-choice, personal communication, August 14, 2018; Rep. of ARCC, personal communication, August 11, 2018)

Another main front that AB Pro-Choice has worked on is targeting the sex education that CPCs have provided within some Alberta public schools. The volunteers of this organization have set up and consolidated their activism on this issue through several phases. First, they have offered online resources packages that informed parents of the content of comprehensive sex education and explained why CPCs' programs failed to meet these standards. In the meantime, they have appealed to parents to sign a petition to present to these public-school boards demanding the removal of existent CPCs' sex-education. After successfully removing these programs from schools, AB Pro-Choice has continued to routinely send out surveys to these school boards' candidates and expose their stances on women's reproductive freedom, in an attempt to prevent new anti-choice board members from endorsing CPCs and allowing them to return to schools. However, AB Pro-Choice believes that in order to fundamentally solve this 
particular problem, the Alberta provincial government needs to establish an official standard for any third-party sex-education presenters, which is currently still nonexistent. (Rep. of AB Pro-choice, personal communication, August 14, 2018; Rep. of ARCC, personal communication, August 11, 2018)

However, ARCC and AB Pro-Choice have not yet successfully addressed another goal- to create regulations for CPCs in Canada. The representatives of both groups spoke of plans to propose statutes during the fall of 2018 and the beginning of 2019, though in slightly different manners. ARCC has modeled a bylaw that requires CPCs to plainly "inform all their clients with a list of what they provide and don't provide", bans them from utilizing ultrasounds, and demands certification of all CPC counselors - since, as of now, many peer counselors who have not been systematically trained, instead of registered psychologists or social workers, serve the female clients at CPCs. The ARCC representative said that they expected to present this bylaw to pilot cities they had chosen. Similarly, AB Pro-Choice is working with the Federation of Associations for Counselling Therapists in Alberta (FACT) (Note 9) - an alliance of professional counselors and therapists - to set up the Alberta College of Counselling Therapists. This college will enable the regulation of CPCs authorized by Alberta provincial legislation. Additionally, AB Pro-Choice is continually reaching out to MLAs (Members of the Legislative Assembly) of New Democratic Party, the current ruling party of Alberta. (Rep. of AB Pro-choice, personal communication, August 14, 2018; Rep. of ARCC, personal communication, August 11, 2018)

While ARCC and AB Pro-Choice have dedicated various forms of efforts to anti-CPC activism, the representatives of both groups concurred that there had been little focus placed on CPCs overall among reproductive justice groups aside from them (Rep. of AB Pro-choice, personal communication, August 14, 2018; Rep. of ARCC, personal communication, August 11, 2018). In the following section, I explain the underlying reasons for this lack of attention.

\subsubsection{Underlying Reasons for Not Addressing CPCs}

The external factors that hinder anti-CPC activism, as all three groups mentioned, are charity restrictions and low resources. According to the three interviewees, most pro-choice groups in Canada are registered as charities, since this status brings advantages of offering tax receipts to donors - thus attracting more funding - and being eligible for more governmental grants. However, in order to maintain their charitable status, they are not allowed by the Canada Revenue Agency to dedicate more than ten percent of their resources to political activities (Government of Canada, 2017). Furthermore, both PPO and AB Pro-Choice cited the strict political audits that the former conservative Harper government implemented under this rule as a factor constraining activists in charities from engaging in anti-CPC movements. Gary from PPO stated, "for more than one year we were under investigation of the government ... from 2007 to 2008 ... and then we became less engaged in such advocacy against CPCs." Yet, even after receiving more funds from the government, these reproductive justice organizations still do not have enough income to allocate for anti-CPC campaigns and are consistently shorthanded. "We have to put up with the Birthright's (Note 10) ads on buses because we can't run ads of our own ... those cost four thousand to five thousand dollars a month," said Gary. On the other hand, AB Pro-Choice and ARCC have been able to launch most, if not all, of the anti-CPC movement in Canada precisely because they regard themselves as political groups and do not seek charity status. However, this positioning also means that these two groups rely solely on funding from the public and membership fees. This fund shortage further leads to their incapability to financially support their members: the workforces for both groups are mainly made up of unpaid volunteers. (Rep. of AB Pro-choice, personal communication, August 14, 2018; Rep. of ARCC, personal communication, August 11, 2018; Rep. of PPO, personal communication, August 12, 2018)

It is worth noting, however, that right before I conducted this research, the Ontario Superior Court of Justice abrogated the political involvement restriction on Canadian charities, determining it as violating charities' freedom of expression (Beeby, 2018). It remains to be seen whether and how this shift will result in a subsequent change in the anti-CPC activism among Canadian reproductive justice groups. Regarding this question, the PPO representative described such a change as "open[ing] a door" (Rep. of PPO, personal communication, August 12, 2018); Ruth from AB Pro-Choice mentioned that, since this court decision, there had been increasing involvement in political issues within the social media of several pro-choice groups, including the SHORE Centre in Ontario (Rep. of AB Pro-choice, personal communication, August 14, 2018; SHORE Centre, 2018).

Meanwhile, many Canadian reproductive justice activists view CPCs as less dangerous or pressing than other reproductive concerns and this belief also informs their lack of focus on CPCs. Most Canadian reproductive justice groups, according to responses from the interviewed activists, do not regard CPCs as an urgent issue, despite being aware of the presence of CPCs. Three main reasons underlie such a judgment. First, many RJ activists hold that $\mathrm{CPCs}$ in Canada exhibit variations from each other, with some not providing misleading information on their 
websites and using less stigmatizing language in counseling, which makes them seem less dangerous as a whole. "Some are better than others ... some websites are more bearable" (Rep. of ARCC, personal communication, August 11, 2018), Sandra from ARCC stated. Second, some pro-choice activists believe that the Canadian political climate and abortion legal history set a stage where CPCs cannot exert very much influence on pregnant women. In Canada, abortion during any stage of the pregnancy has been legalized since the case of R. v. Morgentaler in 1988 (DeLorme, 1991), and it is regulated like any other medical procedure under the Canadian Health Act (Government of Canada, 2018). Moreover, Sandra explained that the current Trudeau government "prides itself on being pro-choice" (Rep. of ARCC, personal communication, August 11, 2018). Regarding this discourse, the AB Pro-Choice representative expressed concerns, insisting, "in Canada we are ... quite complacent about abortion rights ... people don't realize there could be a threat" (Rep. of AB Pro-choice, personal communication, August 14 2018). Third, most pro-choice groups consider the importance of creating equal abortion access, among others, as outweighing the importance of countering CPCs. In Canada, women in rural areas usually have to travel exceptionally far to acquire abortion services in major cities. One way in which ARCC and PPO have tackled this issue is to inform and educate healthcare providers on how to prescribe the abortion pill Mifegymiso (Rep. of AB Pro-choice, personal communication, August 14, 2018; Rep. of PPO, personal communication, August 12, 2018), especially after a range of limitations on its prescription were lifted in November 2017. (For example, the latest permitted time of prescribing Mifegymiso was extended from seven weeks to nine weeks, and practitioners no longer had to perform ultrasounds that could delay abortion pill usage before prescribing this pill (Hounsell, 2017).) It is worth noting that the PPO representative viewed focusing their limited resources on increasing abortion access as a means to indirectly lower the impact of CPCs (Rep. of PPO, personal communication, August 12, 2018). This statement, once again, suggests that for some RJ groups, not focusing on CPCs is a strategic choice owing to the groups' lack of resources. Besides, PPO as an organization also regards the conservative sex-education that might be enforced by the Ontario government more concerning than CPCs' influence (Rep. of PPO, personal communication, August 12, 2018).

\section{Conclusion}

This research shows that, in general, CPCs in Canada have followed a growing trend with regard to their numbers during the past 35 years. Although Canadian reproductive justice groups have realized the threat inherent in CPCs' misleading information, their concealment of real agenda, and the legitimization of their prejudiced sex education in schools, RJ groups as a whole have not focused on CPCs. This lack of focus, as I have argued here, is mainly due to the political engagement restriction that used to be imposed on most of these activist groups; it also arises from RJ groups' viewpoint that the variation among Canadian CPCs lessens their threat as a whole. The liberal Canadian political context drives reproductive justice groups to concern themselves more with abortion access and conservative provincial governments undermining the comprehensive sex education in all public schools. The existent yet limited activism includes lobbying for cutting CPCs' funding from governmental programs, revoking these centers' charitable status through media and letter-writing campaigns, requesting Advertising Standards Canada to ban CPCs' advertisements, and collaborating with parents to remove the conservative sex education offered by some CPCs in public schools. Groups engaging in anti-CPC activism plan to model bylaws with city legislation bodies and provincial organizations to demand CPCs clarify their qualifications and ban them from using ultrasounds. These RJ groups are also planning to develop a set of standards to certify CPCs' counselors.

This paper seeks to advance more scholarly discussions of Canadian CPCs and the corresponding activism, as well as to call for more attention on CPCs by activists in RJ groups in Canada. In the meantime, I need to acknowledge that certain limitations exist in this study. First, this research only collected data for CAPSS-affiliated CPCs accessible online as of August 2018 instead of covering all Canadian CPCs. Second, I might have omitted certain CPCs' closure information if these centers no longer existed in CAPSS's directory after their closure. Due to these two factors, the developing trend of CPCs in Canada that I concluded on might not be entirely accurate. Third, I only interviewed representatives of three groups in this research process, whose answers might not comprehensively represent the reasons why the rest of the groups do not engage in anti-CPC activism. The fourth limitation is that this study did not investigate Canadian CPCs on site. Therefore, variation among CPCs, as mentioned by the interviewed activists, might be an important factor that this research was not able to delve into.

The process and results of this scholarly research also reveal some directions that may be explored in the future. First, researchers may consider conducting on-site "mystery client" investigations of Canadian CPCs to capture a more detailed image of their operation and the tactics CPC counselors use when directly conversing with clients. Second, as the interviewed RJ activists all conceded that they lacked resources and funding for their endeavors, researchers may ask what should be done by the government to make more resources available to these groups. Third, in the future, one might examine whether the lift of the political involvement restriction in July 2018 will 
change the landscape of Canadian anti-CPC activism or even the overall pro-choice activism in Canada.

\section{Acknowledgments}

I wish to acknowledge Professor Carly Thomsen for introducing me to the topic of crisis pregnancy centers and guiding me throughout this research process.

\section{Competing Interests Statement}

I declare that I have no competing or potential conflicts of interest in this study.

\section{References}

Abortion Rights Coalition of Canada. (n.d.). Canadian websites (Pro-choice groups). Retrieved August 8, 2018, from Abortion Rights Coalition of Canada (ARCC-CDAC) website: http://www.arcc-cdac.ca/links.html

Abortion Rights Coalition of Canada. (2017, January 11). Anti-abortion agencies get millions in government funding [Press release]. $\quad$ Retrieved http://www.arcc-cdac.ca/press/ARCC-CDAC-release-jan-11-17-english.pdf

Action Canada for Sexual Health and Rights. (n.d.). About Action Canada. Retrieved August 8, 2018, from Action Canada for Sexual Health and Rights website: https://www.actioncanadashr.org/about-us/\#about_us

Arthur, J. (2009, January). Exposing crisis pregnancy centres in BC. Retrieved from http://www.prochoiceactionnetwork-canada.org/exposing-cpcs-in-bc.pdf

Arthur, J., Bailin, R., Dawson, K., Glenwright, M., Reinhardt-Simpson, A., Sykes, M., \& Zimmer, A. (2016). Review of "crisis pregnancy centre" websites in Canada. Retrieved from http://www.arcc-cdac.ca/CPC-study/CPC-Website-Study-ARCC-2016.pdf

BC Humanist Association. (2016, May 19). A hugely important study from our friends at ARCC has found that of 166 crisis pregnancy centre websites in Canada "96\% (159) revealed a religious affiliation or agenda ... [Facebook status update]. Retrieved from https://www.facebook.com/bchumanist/posts/1024002431022624

Beeby, D. (2018, July 17). CRA loses court challenge to its political-activity audits of charities. Retrieved from CBC News website: https://www.cbc.ca/news/politics/charity-political-audits-cra-lebouthillier-farha-poverty-environmental-gray -liberal-1.4750295

Bryant, A. G., \& Levi, E. E. (2012). Abortion misinformation from crisis pregnancy centers in North Carolina. Contraception, 86(6), 752-756. https://doi.org/10.1016/j.contraception.2012.06.001

Bryant, A. G., Narasimhan, S., Bryant-Comstock, K., \& Levi, E. E. (2014). Crisis pregnancy center websites: Information, misinformation and disinformation. Contraception, 90(6), 601-605. https://doi.org/10.1016/j.contraception.2014.07.003

Bryant, A. G., \& Swartz, J. J. (2018). Why crisis pregnancy centers are legal but unethical. AMA J Ethics, 20, 269-277. https://doi.org/10.1001/journalofethics.2018.20.3.pfor1-1803

Canadian Association of Pregnancy Support Services. (n.d. a). CAPSS core documents. Retrieved August 15, 2018, from Crossroads Pregnancy Centre website: https://web.archive.org/web/20180603164932/http://www.cpcnanaimo.com/CAPSS\%20CORE\%20DOCU MENTS\%202017.pdf

Canadian Association of Pregnancy Support Services. (n.d. b). Find a centre. Retrieved August 1, 2018, from Canadian Association of Pregnancy Support Services website: https://capss.com/our-capss-affiliated-centres/

Chen, A. X. (2013). Crisis pregnancy centers: Impeding the right to informed decision making. Cardozo Journal of Law \& Gender, 19(3), 933-960. Retrieved from https://heinonline.org/HOL/LandingPage?handle=hein.journals/cardw19\&div=37\&id=\&page=

DeLorme, L. (1991). Gaining a Right to Abortion in the United States and Canada: The Role of Judicial Capacities. Berkeley Journal of Sociology, 36, 93-114. Retrieved from http://www.jstor.org/stable/41035444

Gonin, A., Pronovost, V., \& Blais, M. (2014). Enjeux éthiques de l'intervention auprès de femmes vivant une grossesse imprévue au Québec: Discours et pratiques de ressources anti-choix et pro-choix - Rapport de recherche. (Translation: Ethical Issues of intervention with unplanned pregnancy experienced by women living in Quebec: Anti-choice and pro-choice discourse and resource practices - Research report.). Retrieved from http://www.fqpn.qc.ca/main/wp-content/uploads/2014/12/rapport-de-recherche.pdf 
Government of Canada. (n.d.). List of charities. Retrieved August 1, 2018, from Government of Canada website: https://www.canada.ca/en/revenue-agency/services/charities-giving/charities-listings.html

Government of Canada. (2017, October 31). Political activities policy statement cps-022. Retrieved from Government of Canada website: https:/www.canada.ca/en/revenue-agency/services/charities-giving/charities/policies-guidance/policy-state ment-022-political-activities.html

Government of Canada Health Canada. (2018, February). Canada health act annual report 2016-2017 (Health Canada, Author). Retrieved from https:/www.canada.ca/content/dam/hc-sc/documents/services/publications/health-system-services/canada-h ealth-act-annual-report-2016-2017/canada-health-act-annual-report-2016-2017-eng.pdf

Heartbeat International. (n.d. a). Worldwide directory of pregnancy help (Canada as the search criteria). Retrieved August 19, 2018, from Heartbeat International website: https://www.heartbeatinternational.org/index.php?option $=$ com_civicrm\&task=civicrm/profile\&Itemid $=150$

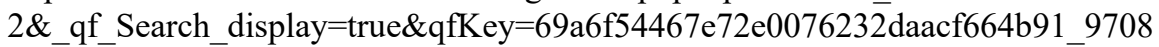

Heartbeat International. (n.d. b). Worldwide directory of pregnancy help (United States as the search criteria). Retrieved August 19, 2018, from Heartbeat International website: https://www.heartbeatinternational.org/index.php?option $=$ com_civicrm\&task=civicrm/profile\&Itemid=150 2\&_qf_Search_display=true\&qfKey=69a6f54467e72e0076232 $\mathrm{daacf664b91 \_ 7609}$

Hill, B. J. (2015). Casey meets the crisis pregnancy centers. The Journal of Law, Medicine and Ethics, 43(1), 59-71. https://doi.org/10.1111/jlme.12196

Holtzman, B. (2017). Have crisis pregnancy centers finally met their match: California's reproductive FACT Act [PDF]. Northwestern Journal of Law \& Social Policy, 12(3), 78-110.

Hounsell, K. (2017, November 7). Health Canada lifts restrictions on so-called abortion pill. Retrieved from CBC News website: https:/www.cbc.ca/news/canada/nova-scotia/restrictions-lifted-abortion-pill-mifegymiso1.4390209

LaRoche, K. J., \& Foster, A. M. (2015). Toll free but not judgment free: Evaluating postabortion support services in Ontario [Abstract]. Contraception, 92(5), 469-474. https://doi.org/10.1016/j.contraception.2015.08.003

Laurier Brantford Women's Centre. (2016, May 20). This is important to keep in mind since you should always know the values of organizations in your area that you... [Facebook status update]. Retrieved from https:/www.facebook.com/laurierbrantfordwomenscentre/posts/543598362478601

Maloney, P. (2017, May 10). Abortion rights coalition of Canada deceitful on crisis pregnancy centres (Post 6) [Blog post]. Retrieved from Run with Life http://run-with-life.blogspot.com/2017/05/abortion-rights-coalition-of-canada_10.html

Paperny, A. M. (2015, Dec 9). Where in Canada can you get an abortion? It's secret — for security reasons. Global News. $\quad$ Retrieved from https://globalnews.ca/news/2351133/where-in-canada-can-you-get-an-abortion-its-secret-for-security-reaso ns/

Rep. of ARCC. (2018, August 11). [Videoconference interview by the author].

Rep. of AB Pro-Choice Coalition. (2018, August 14). [Videoconference interview by the author].

Rep. of PPO. (2018, August 12). [Videoconference interview by the author].

SHORE Centre. (2018, August 23). Have you heard? The government launched a snitch line and website to collect anonymous complaints about teachers teaching sex ed... [Tweet]. Retrieved from https://witter.com/SHORECentreWR/status/1032694104008744961?s=19

Thomsen, C. A., \& Morrison, G. (in press). Abortion as gender transgression: Reproductive justice, queer theory, and anti-crisis pregnancy center activism. Signs.

United States House of Representatives Committee on Government Reform Minority Staff Special Investigations Division. (2006). False and misleading health information provided by federally funded pregnancy resource centers. Retrieved from https:/www.chsourcebook.com/articles/waxman2.pdf

West Coast Legal Education and Action Fund. (2008). Case summary Watson Spratt: R v. Spratt; R. v. Watson, 2008 BCCA 340. Retrieved August 11, 2018, from West Coast Legal Education and Action Fund website: 
http:/www.westcoastleaf.org/wp-content/uploads/2014/11/CASES-2008-R-V-WATSON-SPRATT-Case-Su mmary.pdf

\section{Notes}

Note 1. See Section 5.2.

Note 2. All the information in this section, unless otherwise specified, was collected by me in August 2018.

Note 3.70 out of $231 \mathrm{CPCs}$ in Canada.

Note 4. All the information in this section, unless otherwise specified, was collected by me in August 2018.

Note 5. The two organizations are Alberta Society for the Promotion of Sexual Health (ASPSH) and National Abortion Federation - Canada.

Note 6. This organization is Planned Parenthood Newfoundland \& Labrador. According to Heartbeat International, only one CPC operates in Newfoundland and Labrador as of August 2018 (Heartbeat International, n.d. a).

Note 7. I used Canadian spelling for the keywords.

Note 8. This organization, Fédération du Québec pour le planning des naissances (FQPN), did not provide any materials about their anti-CPC campaigns on their website, Facebook or Twitter either.

Note 9. For more information about FACT Alberta, see https://www.fact-alberta.org/faqs.html

Note 10. Birthright International is another umbrella organization of CPCs in Canada.

\section{Copyrights}

Copyright for this article is retained by the author(s), with first publication rights granted to the journal.

This is an open-access article distributed under the terms and conditions of the Creative Commons Attribution license (http://creativecommons.org/licenses/by/4.0/). 